\title{
Study on the Grading Treatment Model of "Health Management Center" in the Perspective of Sports-Health Care Integration
}

\author{
Junjiang Sun ${ }^{1,2 *}$, Anna Szumilewicz ${ }^{2}$ \\ 1 Yunnan University of Business Management, Kunming 650000; sun.junjiang@awf.gda.pl \\ 2 Gdansk University of Physical Education and Sports, Gdansk 80-309. \\ * Correspondence: sun.junjiang@awf.gda.pl; Tel.: 0086-18187104625
}

\begin{abstract}
Background: With continuous globalization and modernization of people's lives, lifestyle has changed dramatically, with decreased physical activity and increased unhealthy eating patterns in many nations throughout the world. With the COVID-19 pandemic and changes taking place in people's health and lifestyles around the world, the need for rehabilitation is expected to rise in the coming years. (2) Methods: This paper analyzes the integration model of sports and health care using theoretical analysis, literature reviews, logical reasoning, and other methods. (3) Results: The integration of sports and health care in China has entered the stage of practical implementation after many years of development, forming a few representative integration patterns. Governments, communities, community hospitals, hospitals, and third-party institutions are the main participants, with the community playing an important role in the integration. Pharmacies, sports venues, and schools with sufficient staff have a relatively low participation rate. (4) Conclusion: The grading treatment has been applied in health management and sports rehabilitation, based on the development of digital medicine, a government-led grading treatment model of "health management center" can promote the participation of multiple subjects in the integration of sports and health care, solving the problems existing in the current integration process to a certain extent.
\end{abstract}

Keywords: integration of sports and health care; sports; health; community

\section{Introduction}

At present, Chinese citizens have a low level of health understanding, and unhealthy lifestyles such as smoking, alcohol abuse, lack of exercise, and an unbalanced diet are frequent, resulting in increasingly prominent issues of diseases. In particular, chronic diseases, such as cardiovascular and cerebrovascular diseases, cancer, chronic respiratory diseases and diabetes, have caused $88 \%$ of the total death toll and caused more than $70 \%$ of the total disease burden, seriously endangering people's health [1]. China has pushed the shift away from "treating diseases as the central task" and toward "people's health as the central task". With the improvement of people's living levels, the demand for improved life quality is increasing, and people are paying more attention to health, disease prevention, health care and rehabilitation. Exercise is medicine has been deeply rooted in people's hearts.

Since the deepening of reform and opening-up, China has witnessed rapid economic and social progress, and the people's material living standards have been substantially improved. People are becoming increasingly concerned about their health, and their desire to promote health through fitness is growing. Year after year, the number of people who engage in regular physical activity rises. However, China also faces a series of problems, including the unbalanced regional development of national fitness, inadequate public service supply, short of sports ground and low utilization of problems. Residents 
also face issues such as "where to go to exercise", "how to scientifically exercise" and "how to rehabilitate", lacking effective guidance.

Through consulting the relevant literature on sports and medicine fusion, the literature mainly focuses on the connotation and existing problems of sports and medicine fusion, and there are few studies on the specific path of fusion. This paper analyzes the development of integration of sports and health care and the current pilot model of sports and medical integration in China. We propose the government-led grading treatment model of "Health Management Center" and explore the implementation path of sports and health integration. The aim is to provide ideas and references for the implementation of national fitness and healthy China.

\section{Materials and Methods}

\subsection{Search Strategy}

The An electronic search of the literature was conducted in August 2021-January 2022.The following databases were included: Web Science, CNKI, MEDLINE with Full Text, SPORTDiscus with Full Text. Search strategies using combinations of subject headings and keywords were developed to identify appropriate studies. Search terms included but were not limited to: "combination of sports and medicine", "integration of sports and health care", "health management", "graded diagnosis and treatment", "athletic rehabilitation or exercise rehabilitation or sports rehabilitation".

\section{2. theoretical analysis and logical reasoning}

Reference to health management, PCIC (People-Centered and Integrated Health Care), hierarchical medical system three theories, as a theoretical basis, combining the development and practice of sports and medical integration, the positioning of sports in health promotion, application of grading treatment in health management and sports rehabilitation, and the development of digital medicine, this paper explores the mode of sports and medical integration by using theoretical analysis and logical reasoning.

\section{Results}

\subsection{Analysis of sports and health care integration development}

The integration of sports and health care was initially the "combination of sports and medicine", which originated in the United States. American health professionals first began to explore the feasibility of applying medical knowledge to sports in the 19th century, while the research in China was initiated in the early 21st century [2]. The "combination of sports and medicine" was first widely adopted in the fitness industry, encouraging people to use exercise instead of medical treatment to restore their health. The "combination of sports and medicine" stems from the health system with drug therapy as the core and prioritizes treatment, which is the initial stage of the integration of sports and health care.

In 2014, China promoted "national fitness" as a national strategy. In 2016, "Healthy China 2030" outlined a clear plan to enhance people's physical fitness by "extensively carrying out national fitness campaigns, strengthening the integration of sports and health care, non-medical health intervention, and promoting sports activities among key population"[3]. For the concept of "integration of sports and health care", the definition is different since the research perspective is different. The integration of "sports" and "health care" is the integration of exercise health resources and medical health resources, achieving the optimal allocation of health promotion. Specifically, it is the comprehensive application of sports technology, medical technology and other health promotion means to people's scientific fitness, disease prevention, disease treatment and rehabilitation, in order to get the whole lifecycle of health promotion [4][5]. The "integration of sports and 
health care" based on "national fitness" and "Healthy China", elevating the importance of national health status. The "integration of sports and health care" is more in-depth and comprehensive than the "combination of sports and medicine", seeking more diverse ways of integrating sports and health care on the original basis. The "integration of sports and health care" is the initial and developing stage of the integration of sports and medical care.

August 3, 2021, China issued the "National Fitness Program (2021-2025)", which stated to explore the establishment of exercise to promote health model that sports, health and other departments with the participation of the whole society. Efforts will be made to extend the coverage of integrated sports and health care services to the community level, support the establishment of scientific fitness clinics in community medical and health institutions. Theories and scientific and practical innovations in the integration of sports and health care are advanced, and the typical development experience of integrated sports and health care is popularized [6]. The "14th Five-Year Plan and 2035 Vision" has placed the construction of a healthy China and a strong country in sports in a prominent position by promoting "moving forward the health barrier and deepening the integration of sports and health care". October 21, 2021, the General Office of the NHC promulgated the "Pilot Work Plan for Rehabilitation Medical Services", proposed to accelerate the development of rehabilitation medical services, effectively increase the supply of rehabilitation medical services, and meet the diverse needs of the public for rehabilitation medical services [7]. The essence of the "integration of sports and health care" is a mode of promoting health through the cooperation of sports and health departments with the participation of the whole society. Relevant policy guidance has been put forward from the establishment of fitness clinics, the transformation of some primary and secondary hospitals into rehabilitation hospitals, the establishment of rehabilitation medical centers and home rehabilitation medical treatment, to the construction of rehabilitation medical disciplines, personnel training, and the price and payment mechanism of rehabilitation medical services. The "integration of sports and health care" explores the diverse and specific implementations of the integration of sports and health care, which enters the practical development stage of sports and health care integration.

\subsection{Practice analysis of sports and health care integration}

With the introduction of relevant national policies, the deepening of research, and the academic discussion of sports institutions and medical institutions, the integration of sports and health care has officially moved from the conceptual stage to the pilot stage. Local governments and departments have also carried out exploratory development and formed some outstanding representative institutions.

The grass-root pilot of sports and health care integration mainly focuses on three major categories, including sports and health care integration in the community led by the sports department, the integration in sports prescription outpatient department led by the medical department, and the integration of services purchased by government and operation covered by market, as in Table 1. Governments, communities, community hospitals, general hospitals, and third-party institutions are the main participants, with the community being the key member of the integration. The participation of pharmacies, sports venues, and schools with sufficient staff is relatively low. From the relevant research and the problems in the pilot, there are still prominent problems in the integration of sports and health care, such as institutional constraints, incomplete top-level design, insufficient funds and equipment, and insufficient integration and cognition, which need to be addressed [8][9]. 
Table 1. Pilot mode of Chinese sports and medical integration.

\begin{tabular}{|c|c|c|c|}
\hline Pilot a & Pilot path model & Features & Problems \\
\hline Beijing & $\begin{array}{l}\text { Sports bureau, com- } \\
\text { munity and three-A } \\
\text { hospital linkage }\end{array}$ & $\begin{array}{l}\text { (1) The allocation of special funds governed by the } \\
\text { State General Administration of Spor } \\
\text { (2) Guidance from fitness experts and authoritative } \\
\text { doctors } \\
\text { (3) Comprehensive diagnosis and treatment program - } \\
\text { hospital drug prescription - community sports fitness } \\
\text { [10] }\end{array}$ & $\begin{array}{l}\text { (1) Government support, high dependence of } \\
\text { organization and funds on the government, dif- } \\
\text { ficulty to self-management } \\
\text { (2) difficult to large-scale promotion [10] }\end{array}$ \\
\hline Shanghai & $\begin{array}{l}\text { Sports bureau, com- } \\
\text { munity, and commu- } \\
\text { nity hospital linkage }\end{array}$ & $\begin{array}{l}\text { "1+1+2" Community Work Team, Government (policy) } \\
-1 \text { community doctor and } 1 \text { social sport instructor, } 2 \\
\text { self-management team leaders to establish team ser- } \\
\text { vices }\end{array}$ & $\begin{array}{l}\text { (1) Limited ability of community instructors and } \\
\text { doctors in intervention programs } \\
\text { (2) Not strong enough awareness of citizens and } \\
\text { limited sports venues[10] }\end{array}$ \\
\hline Anhui & $\begin{array}{l}\text { Sports bureau, com- } \\
\text { munity, and sports } \\
\text { technology enterprises } \\
\text { linkage }\end{array}$ & $\begin{array}{l}\text { (1) Smart community sports service system built for } \\
\text { information sharing } \\
\text { (2) Treatment plans made by fitness professionals and } \\
\text { doctors, psychological counseling by community in- } \\
\text { structors } \\
\text { (3) Focus on process management }\end{array}$ & $\begin{array}{l}\text { Supported by government funds, the whole pro- } \\
\text { cess for free, high dependence of organization and } \\
\text { funds on government.[10] }\end{array}$ \\
\hline $\begin{array}{l}\text { Guang'anmen } \\
\text { Hospital of } \\
\text { Beijing City }\end{array}$ & $\begin{array}{l}\text { Hospital respiratory } \\
\text { department, rehabilita- } \\
\text { tion instructor, the site } \\
\text { inside and outside the } \\
\text { hospital }\end{array}$ & $\begin{array}{l}\text { (1) Chronic respiratory disease clinic } \\
\text { (2) Whole process intervention by doctors and rehabil- } \\
\text { itation instructors[11] }\end{array}$ & $\begin{array}{l}\text { (1) Limited space and limited number of people } \\
\text { intervened } \\
\text { (2) Limited outpatient personnel and price }\end{array}$ \\
\hline $\begin{array}{l}\text { Shanghai Elderly } \\
\text { "sports and } \\
\text { Health care Inte- } \\
\text { gration" center }\end{array}$ & $\begin{array}{l}\text { The government pro- } \\
\text { vides the free venue, } \\
\text { enterprise responsible } \\
\text { for operation and } \\
\text { management }\end{array}$ & $\begin{array}{l}\text { (1) Public construction and private operation, entrusted } \\
\text { management, service purchases, and other ways } \\
\text { (2) Modern science and technology and information } \\
\text { means for the establishment of the elderly sports health } \\
\text { archives and database }\end{array}$ & d(1) High dependence on government funding \\
\hline $\begin{array}{l}\text { Wuhan "Jiang- } \\
\text { cheng Fitness } \\
\text { E-home" }\end{array}$ & $\begin{array}{l}\text { Government invest- } \\
\text { ment and market op- } \\
\text { eration mode }\end{array}$ & $\begin{array}{l}\text { (1) Throughout the whole process of physical fitness } \\
\text { (2) High level of specialization } \\
\text { (3) High level of intelligence[12] }\end{array}$ & $\begin{array}{l}\text { Insufficient participation of hospital, insufficient } \\
\text { responsibility division, and hierarchical man- } \\
\text { agement }\end{array}$ \\
\hline
\end{tabular}

3.3. The "health management center" grading treatment mode of sports and health care integration led by government

\subsubsection{Theory Basis}

With reference to health management, PCIC (People-Centered and Integrated Health Care), and grading treatment, the path of sports and health care integration was analyzed. The concept of health management is the process of continuously improving people's health or disease through health information collection, detection, evaluation, personalized supervision and management, and intervention [13]. PCIC means people-centered and integrated health care, which was first proposed by the World Health Organization (WHO) in 2015, referring to the integration of various health services management and service delivery that includes health promotion, disease prevention, treatment and hospice care, and the consistent services to patients throughout their lives by coordinating all levels and types of medical institutions based on their health needs [14]. Both health management and PCIC prioritized people-centered health as a goal, stressing that health information collection, testing, and assessment (physical, medical testing and assessment) should be conducted before health interventions and emphasizing continuity and integration.

The connotation of the grading treatment system can be summarized into 16 words, that is, primary treatment at the grass-roots level, two-way referral, separation of emergency and slow treatment, and linkage between the upper and the lower levels [15]. In 2017, General Secretary Xi Jinping made it clear at the National Hygiene and Health Conference that the grading treatment system is at the top of the five basic medical and health care systems, which should be vigorously promoted. To establish the grading 
treatment system, primary care and referral at the grass-roots level for the chronic disease, common disease, and frequently-occurring disease need to be realized. Coordinated urban and rural medical and health service systems with reasonable layout, optimized level, and perfect function should be established. Combining with the characteristics of disease diagnosis and treatment, scientific, appropriate, continuous, and efficient medical services should be provided based on the requirements of patients in the prevention, treatment, rehabilitation, and nursing.

\subsubsection{Positioning of sports in health promotion}

The World Health Organization (WHO) stated in a report that the right amount of regular exercise can reduce premature death, help prevent and reduce chronic diseases, promote mental health, and help prevent and control bad habits. Researchers confirmed that exercise can play a positive role in disease prevention and rehabilitation through exercise intervention in 26 diseases [16]. Therefore, moderate exercise can not only promote physical health, achieve the purpose of fitness, and intervene in chronic diseases, but also play a role in the rehabilitation of special diseases. The Global Plan of Action developed by the World Health Organization (WHO) also emphasizes that sports participation is a key intervention for the prevention of NCDS, which has increasingly become a policy tool for promoting people's health [17]. Physical exercise and rehabilitation sports are two different forms of physical health intervention [18], which are indispensable to health and the health management system. With the development of preventive medicine and health care medicine, the active health mode centered on health promotion has become the mainstream instead of the passive medical mode centered on disease treatment. The health promotion function of sports has attracted much more attention from the medical circle and has been brought into the category of health management of non-medical active health intervention.

3.3.3. Application of grading treatment in health management and sports rehabilitation

According to the CWPAS health management system (check, warning, prevention, assessment, overall solution), through health assessment and disease risk assessment, special physical examination, and early warning analysis, disease risk can be divided into four risk levels: low risk, medium risk, high risk, and extremely high risk. Meanwhile, according to the natural history of chronic diseases, different measures should be taken to prevent the occurrence, development and deterioration of diseases, namely three-level prevention, including primary prevention (etiological prevention), secondary prevention ("three early" prevention) and tertiary prevention (clinical prevention) [19].

Grading treatment has been widely used in the field of sports rehabilitation. The perfect three-level rehabilitation medical network is the common mode of the rehabilitation medical service system in developed countries and regions. The three-level rehabilitation medical service system in the United States can be roughly divided into acute rehabilitation institutions, post-acute care (PAC) institutions and longtime care (LTC) institutions. The three-level rehabilitation medical service system in UK consists of emergency hospital (first diagnosis), specialized rehabilitation hospital (inpatient rehabilitation) purchased by the government, and community rehabilitation. A rehabilitation process based on functional evaluation is established between the three-level institutions, thus forming a rehabilitation medical complex with interconnection between the upper and lower levels [20]. In Hong Kong, as in developed countries, the rehabilitation medical service system is divided into three levels: regional hospitals and rehabilitation hospitals/centers, community rehabilitation services (day hospitals or specialist clinics), and long-term care hospitals (including sanatoriums and nursing homes), providing lifelong care services. Studies have also shown that grading treatment system plays an important role in promoting patients to master the knowledge of disease occurrence, treatment, nursing and rehabilitation, and benefits medical staff to guide and quality control the rehabilitation training of patients [21]. Literature suggested that grading treatment network platform (hospital-community-family) mode has achieved good results in chronic disease management [22]. Three-level rehabilitation has been applied in diagnosis and 
treatment of cardiac rehabilitation, stroke, chronic coronary syndrome patients [23], diabetic microangiopathy[24], and osteoporosis, which can improve patients' quality of life and their mastery of rehabilitation nursing knowledge.

At present, it is suitable to promote the application of three-level rehabilitation network. "Primary rehabilitation" refers to the routine treatment and early rehabilitation of patients in the hospital emergency room or neurology department. "Secondary rehabilitation" means the rehabilitation of patients in rehabilitation wards or rehabilitation centers. "Tertiary rehabilitation" refers to continuing rehabilitation treatment in the community or at home. The concept of grading treatment proposes to provide scientific, appropriate, continuous, and efficient diagnosis and treatment services based on patients' different needs of prevention, treatment, rehabilitation, and nursing, forming an integrated rehabilitation intervention model, as shown in Figure 1.

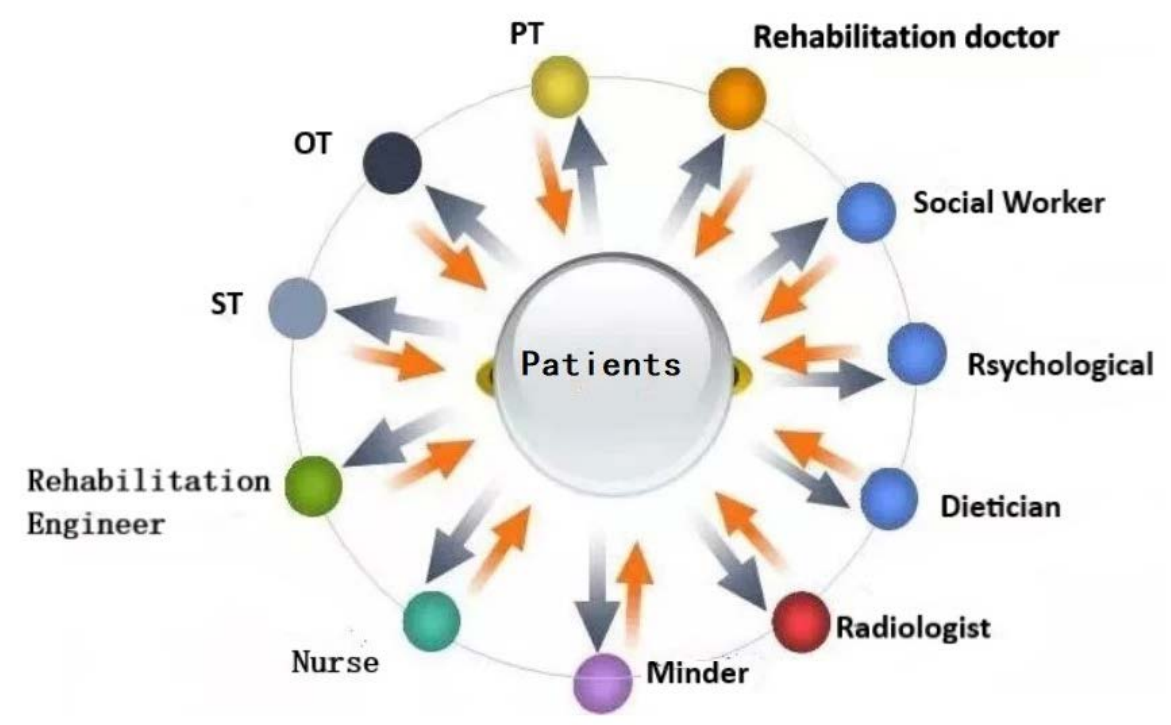

Figure 1. Patient-centered rehabilitation intervention model.

\subsubsection{Development of digital medicine}

Currently, "digitalization" is regarded as a new engine to enhance the quality and efficiency, which has been widely accepted around the world and in all walks of life. In the field of sports medicine, successful cases of digitalization clinical practice have gradually emerged. Application technologies such as mobile applications, wearable devices, intelligent devices, intelligent machines, telemedicine, artificial intelligence, big data, system interoperability, virtual reality, and augmented reality [25], digital empowerment is the key technology to achieve this transformation. Digital medicine is the use of digital tools to upgrade the practice of medicine, promising to transform health care and promote human well-being. At the heart of this revolution is the development of technological solutions to monitor, process and integrate big data from individuals and groups to help address the health issues and challenges faced by patients, clinicians and health systems [26]. In terms of triage, trial application of Babylon in the UK-a chat robot based on artificial intelligence, a classification tool, can distinguish patients between who need review and who need referral. Classification based on the artificial intelligence theoretically can help to reduce the burden of health care system and allocate the resources directly to patients who are most in need. With reference to the digital and intelligent holistic healthcare model based on medical health guidance published in the 2019 Nature journal (Figure 3) [27], the multi-source (meta-) multi-layer spatio-temporal factors affecting individual health are included. With the virtual health prescription suggestions output by intelligent deep learning algorithms, the future AI virtual coach can interact with users only by voice. Ultimately, when all personal data and the totality of 
the medical literature can be considered together, patients can be offered a holistic approach to prevention. Through digital development, it provides more possibilities for "health management center" grading treatment system.

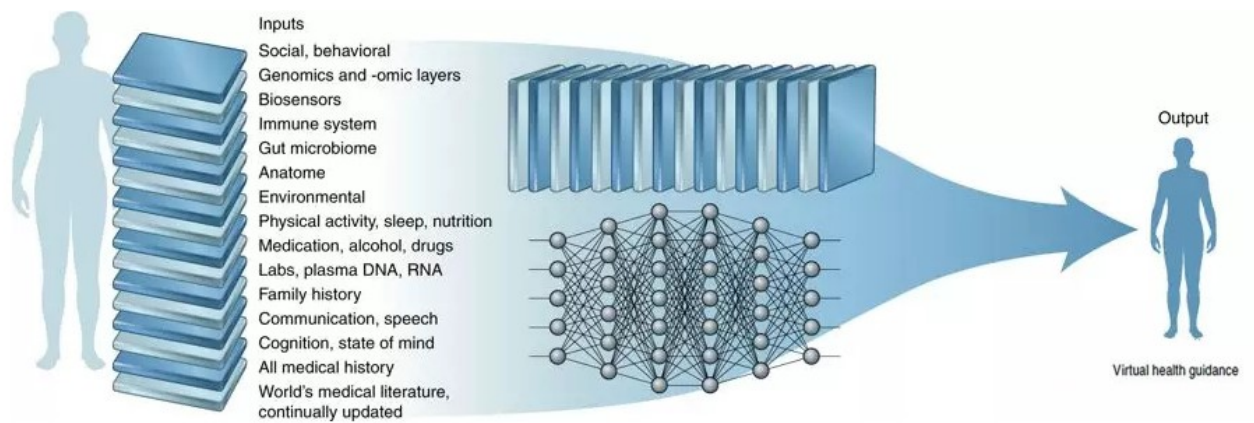

Figure 2. Digital Health Coaching Model Based on Multiple Data Input and Algorithms [27].

3.3.5. Government-led "health management center" grading treatment mode based on big data

Based on the development of "digital" technology, CWPAS health management system, PCIC, the concept of grading treatment, as well as the existing problems in the integration of sports and health care in China and the development needs of the integration of sports and health care, a "full-cycle sports and health care integrated health management grading treatment model" (as in Figure 3) is conceived according to the classification of Chinese hospitals, physical examination and rehabilitation in hospital scenarios. This model expects to achieve health intervention for different groups of people. This mode is based on information technology, led by government, coordinated by sports and medical institutions, with the participation of the whole society. It is centered on the health of the citizens, forming an integrated full cycle health management mode including examination, early warning, prevention, assessment, and rehabilitation, which can promote the top design, improve the fragmented management, and deepen the integration of sports and medical institutions to a certain extent.

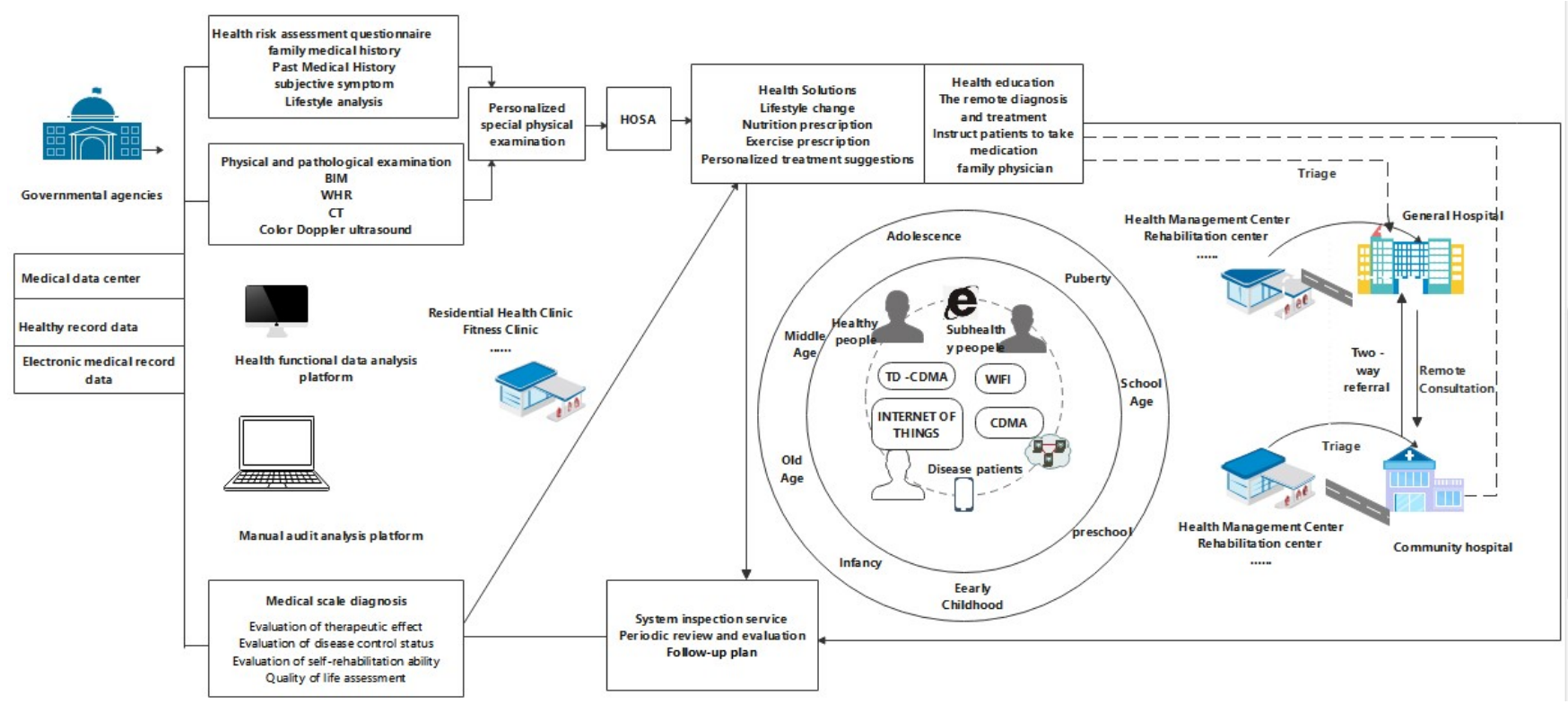

Figure 3. Concept diagram of full-cycle integrated health management grading treatment model. 


\section{Discussion}

The findings of this study show that after many years of development, the integration of sports and health care in China has entered the stage of practical implementation from connotation research and integration exploration, forming a few representative integration patterns. Governments, communities, community hospitals, hospitals, and third-party institutions are the main participants, with the community playing an important role in the integration. Pharmacies, sports venues, and schools with sufficient staff have a relatively low participation rate. Institutional restrictions, top-level design flaws, a lack of capital and equipment, insufficient integration, cognition, and other issues still exist.

The "sports and health care integration" has entered the practical development stage that multiple subjects participate in the integration, this paper reference to health management, PCIC (People-Centered and Integrated Health Care), hierarchical medical system three theories, To provide theoretical support for government-led "health management center" grading treatment mode With the development of modern information technologies such as the Internet, big data of the Internet of Things, cloud computing and artificial intelligence, as well as the development of digital medicine, multi-sectoral collaboration has been strongly guaranteed. China's hierarchical diagnosis and treatment system has also achieved phased results, providing implementation guarantee for the establishment of government-led grading treatment model of "health management center".

At present, COVID-19 is still serious, and global health is affected by the three trends of population aged, disorderly rapid urbanization and globalization [28]. At the same time, various countries and regions have paid more and more attention about healthy lifestyle and sports health promotion and have issued exercise guidelines to promote national exercise. In this background, there are a variety of situations in terms of physical activity. First, researches show that during the initial phase of the COVID-19 outbreak, nearly $60 \%$ of Chinese citizens engaged in inadequate physical activity [29], WHO statistics reveal that one in four adults, and four out of five adolescents, do not currently get enough physical activity, more than 1.4 billion adults worldwide are at risk of disease from not doing enough physical activity. Second, the possibility for people to take part in physical activity is uneven and unfair this inequity has only gotten worse during the COVID-19 pandemic[30].Third, along with relevant policies were promulgated in various countries, people pay more attention to sports, love sports more, and sports injuries are also increasing. Fourth, with changes taking place in the health and characteristics of the population worldwide, more people are living with chronic diseases such as diabetes, stroke, and cancer. At the same time, the ongoing incidence of injury (such as a burn) and child developmental conditions (such as cerebral palsy) persist. These health conditions can impact an individual's functioning and are linked to increased levels of disability, for which rehabilitation can be beneficial [31].

Exercise confers a plethora of health benefits that are well documented, the study shows that for the 168 nations included in this study, the global median PFP was $15.0 \%$, equating to 3.9 million premature deaths averted per year [32]. We all know that sports bring a lot of benefits to people, But too much exercise can also be harmful, a study published in 《Cell Metabolism》 showed that normal exercise is good for mitochondrial function in the short term, but excessive exercise training causes mitochondrial functional impairment and decreases glucose tolerance in healthy[33].there have been an emerging number of reports suggesting that intense exercise may have an adverse impact on an otherwise normal heart[34].According to the above studies, exercise needs appropriate dosage to promote health, and appropriate exercise prescription needs to be formulated.

Experts claim, in many ways, it's useful to think of exercise as a medicine, just as prescribe drugs for high blood pressure and cholesterol, we should prescribe exercise prescription and pay for exercise. Exercise may be considered as the safest, cheapest, and 
most potent therapy that a physician can prescribe to manage [35]. Exercise is like a drug; you can do too much or not enough, there's growing evidence that some endurance athletes do so much exercise that they hurt themselves. Sports clinic, fitness clinic and health management center are still in the exploratory development stage How can exercise dosage be prescribed like medicine, need further exploration. WHO also stressed that stronger partnerships across sectors to deliver effective programs, services and safe environments that engage and support everyone to be active stronger governance structures and regulations to ensure environments support safe physical activity and inclusive programs and sport; and broader, deeper and innovative financing mechanisms to build sustainable strong system that can provide physical activity and sport for all ages and abilities[30].At the same time, rehabilitation is an area of health-related services, which has the characteristics of multi-discipline and cross-field, and covers the whole life cycle of the population. Rehabilitation is an important part of the modern health service system, and is of great significance in promoting the realization of the United Nations 2030 Sustainable Development Goals [36].

\section{Conclusions}

This The integration of sports and health care in China has entered the stage of practical implementation forming a few representative integration patterns achieved certain results, but there are also certain problems. Based on the development of digital medicine, a government-led grading treatment model of "health management center" can promote the participation of multiple subjects in the integration of sports and health care, solving the problems existing in the current integration process to a certain extent, explore the implementation path of sports and health integration, but it still needs be certificated and improved in practice.

Author Contributions: "Conceptualization, S.J. and A.S.; methodology, A.S; software, S.J.; validation, S.J., A.S.; formal analysis, S.J.;writing-original draft preparation,S.J.;writing-review and editing,S.J.; visualization, S.J.; supervision,A.Z.; project administration, Yunnan University of Business Management.;All authors have read and agreed to the published version of the manuscript."

Funding: This research was funded by Yunnan Provincial Department of Education Science Research Fund Project, grant number 2022J1286 .

Institutional Review Board Statement: Not applicable

Informed Consent Statement: Not applicable

Data Availability Statement: All data used for this study is presented in Tables 1 and Figure1,3.

Conflicts of Interest: The authors declare no conflict of interest.

\section{References}

1. The State Council, Opinions of The State Council on the Implementation of Healthy China Action (2019-2030) [EB/OL]. (2019-06-24)[2019-07-15]. http://www.gov.cn/zhengce/content/2019-07/15/content_5409492.htm

2. Zeng Jien, Yang Mingfa. Analysis of the Relationship between "Body-medicine Integration" and "Body-Medicine Integra tion" [J]. Journal of Qinghai Normal University: Natural Science Edition, 2019, 35(1):4.DOI:10.16229/j.cnki.issn1001-7542.2 019.01.016.

3. Outline of "Healthy China 2030" Plan [M] Beijing: People's Publishing House, 2016:10

4. Guo Jianjun. Research and Suggestion of Sports and Medical Docking in the Construction of Healthy China [J]. Journal of Chronic Diseases, 2016, 17(10): 1067-1073.DOI:10.16440/j.cnki.1674-8166.2016.10.002.

5. Xiang Yuhong, Li Chengwei. Development of School Physical Education in China under the "Integration of Physical E ducation and Medicine" [J]. Chinese Journal of Physical Education, 2017, 24(05): 76-79.doi:10.16237/j.cnki.cn44-1404/g8.20 17.05.009.

6. State Council, Circular of The State Council on Printing and Distributing the National Fitness Plan (2021-2025) [EB/OL]. (2021-07-18) [2021-08-03]. http://www.gov.cn/zhengce/content/2021-08/03/content_5629218.htm 
7. General Office of the National Health Commission, Notification on the Pilot work on Rehabilitation Medical Services [EB/OL]. (2021-10-21). http://www.nhc.gov.cn/yzygj/s7653pd/202110/9af02fe668e74aa3a0271e425ef0ea58.shtml

8. Jia Sangang, Qiao Yucheng. Sports and Medicine Integration: Dilemma and Outlet of Operation Level [J]. Sports Research, 201, 35(01): 29-35.doi:10.15877/j.cnki.nsic.20210309.002.

9. Yang Jixing, Chen Jiaqi. Analysis of Restricting Factors and Path Construction of Sports and Medical Integration [J]. Sports Culture Guide, 2019 (4) 20-21

10. Li Jing, Zhang Li. Research on the Experiences, Realistic Challenges, Countermeasure of Chronic Disease Prevention and Treatment of Integration of Sports and Medicine in Construction of Healthy China [J]. Sports Science, 2020 (40):73-82. DOI: 10.16469 j.carol carroll ss. 202012007

11. Feng Lei. Integration of Physical Education and Medicine: A New Perspective on Sports [N]. China Sports Daily, 2019-7-25(5).

12. Fang Ni, Chen Yinqiao. Research on Basic Function Design and Function Realization of Scientific Fitness Service in Urban Community: A Case Study of Wuhan Jiangcheng Fitness Center [C]. Jiangxi: School of Physical Education, East China Jiaotong University, 2016

13. Lou Peian. Overview of Health Management [J]. China School Medicine, 2008 (1):117-119.

14. WHO. WHO Global Strategy on People-Centred and Integrated Health services [EB/OL]. (2015-06-10). http://apps.whointirishandle/10665/155002.

15. Guo Yanhong. Chinese Journal of General Practice, 2017, 20 (1):1-5.

16. Luan X, Tian X, Zhang H, et al. Exercise as a prescription for patients with various diseases[J]. Journal of sport and health science, 2019, 8(5): 422-441.https://doi.org/10.1016/j.jshs.2019.04.002.

17. WHO. WHO Global Strategy on People-Centred and Integrated Health Services [EB/OL]. (2015-06-10). http://apps.who.int/iris/han-dle/10665/155002.

18. Dai Z P, Ma W P, "Sports+Medical+Nursing" Pathway Construction of Elderly Health Intervention [J]. Journal of Aging Research, 2018, 6(09):55-66.

19. Ma Wenling, Liu Wei, Li Tieling. Early Warning and Intervention of Cardiovascular and Cerebrovascular Diseases: An Introduction to CWPAS Health Management System [M]. Military Medical Science Press, 2014.

20. Zhao Bing, Zhou Xuan, Chen Nan, Yang Yuqi, Liang Juping, Huang Pei, Sheng Jianqin, Song Yuanyuan, Du Qing. Chinese Journal of Physical Medicine and Rehabilitation, 2020, 42(11):1038-1040.

21. Zhong Yanping. Nursing Practice and Research, 2017, 14(20):124-126.

22. Xu Yujie, Liu Xiaoxia, Zhang Hong, Research Progress of Hospital-Community-Family Integrated Management Model for Hyperuricemia Patients [J] Journal of Nursing, 2019, 34(19):99-101.

23. Wang J, Wang J, Wang J, et al. The Role of Exercise Rehabilitation in Patients with Chronic Coronary Syndrome [J]. Chinese Journal of Interventional Cardiology, 201, 29(07):361-370.

24. Wang J, Wang J, Wang J, et al. Microangiopathogenesis and Microangiopathogenesis of Diabetes Mellitus [J]. Chinese Journal of Medical Frontiers, 201,13(06):16-38.

25. Rigamonti L, Albrecht U V, Lutter C, et al. Potentials of digitalization in sports medicine: a narrative review[J]. Current sports medicine reports, 2020, 19(4): 157-163.doi: 10.1249/JSR.0000000000000704

26. Hu Haixu, Yang Guoqing. Digital Transformation: Ignite the New Engine of Contemporary Competitive Sports Training Reform [J]. Journal of Beijing Sport University, 201,44(11): 81-98.doi: 10.19582/j.cnki.11-3785/g8.2021.11.009.

27. Topol E J. High-performance medicine: the convergence of human and artificial intelligence[J]. Nature medicine, 2019, 25(1): 44-56. https://doi.org/10.1038/s41591-018-0300-7

28. WHO. Global recommendations on physical activity for health. Geneva: World Health Organization; 2010.

29. Qin, F.; Song, Y.; Nassis, G.P.; Zhao, L.; Dong, Y.; Zhao, C.; Feng, Y.; Zhao, J. Physical Activity, Screen Time, and Emotional Well-Being during the 2019 Novel Coronavirus Outbreak in China. Int. J. Environ. Res. Public Health 2020, 17, 5170. https://doi.org/10.3390/ijerph17145170

30. WHO calls for better and fairer opportunities for physical activity to improve health [EB/OL]. (2021-10-14). https://ww w.who.int/news/item/14-10-2021-who-calls-for-better-and-fairer-opportunities-for-physical-activity-to-improve-mental-and-p hysical-health

31. Rehabilitation [EB/OL]. (2021-11-10). https://www.who.int/news-room/fact-sheets/detail/rehabilitation

32. Strain T, Brage S, Sharp S J, et al. Use of the prevented fraction for the population to determine deaths averted by exi sting prevalence of physical activity: a descriptive study[J]. The Lancet Global Health, 2020, 8(7): e920-e930.https://doi.o $\mathrm{rg} / 10.1016 / \mathrm{S} 2214-109 X(20) 30211-4$.

33. Flockhart M, Nilsson L C, Tais S, et al. Excessive exercise training causes mitochondrial functional impairment and decreases glucose tolerance in healthy volunteers[J]. Cell metabolism, 2021, 33(5): 957-970. e6.https://doi.org/10.1016/j.cmet.2021.02.017.

34. Merghani A, Malhotra A, Sharma S. The U-shaped relationship between exercise and cardiac morbidity[J]. Trends in cardiovascular medicine, 2016, 26(3): 232-240.https://doi.org/10.1016/j.tcm.2015.06.005

35. World Health Organization. Rehabilitation 2030: A Call for Ac-tion Geneva [EB/OL]. World Health Organization, 2017. [2018-08-02]. https://www.who.int/publications/m/item/rehabilitation-2030-a-call-for-action

36. QIU Zhuo-ying, et al. Research on Rehabilitation Guidelines Using World Health Organization Family International Classifications:Framework and Approaches.[J].Chin J Rehabil Theory Pract, 2020, 26(2). 